\title{
Mesin Kristalisator Pembuatan Suplemen Pencegah Covid 19 di Desa Kemuning Lor, Jember
}

\author{
Crystallization Machine for Making Supplements to Prevent Covid 19 in Kemuning Lor Village, \\ Jember
}

\author{
Andik Irawan ${ }^{1 *}$, Dicky Adi Tyagita ${ }^{1}$, Ridwan Iskandar ${ }^{2}$ \\ ${ }^{1}$ Jurusan Teknik, Politeknik Negeri Jember, Indonesia \\ ${ }^{2}$ Jurusan Manajemen Agribisnis , Politeknik Negeri Jember, Indonesia \\ *andik_irawan@polije.ac.id
}

\begin{abstract}
ABSTRAK
Kota Jember merupakan salah satu kota dengan tingkat pasien positif COVID 19 yang belum mengalami penurunan yang signifikan dengan berbagai media penularan yang tidak nampak, berbagai cara dilakukan untuk mencegah agar COVID 19 tidak menyebar dengan cepat. Beberapa cara pencegahan yakni dengan penyemprotan desinfektan, penggunaan saniter yang tepat, penggunaan suplemen herbal untuk pencegahan agar meningkatkan imun, dan pemantauan rutin diwilayah masing - masing. RT 5 Dusun Kopang Krajan Desa Kemunig Lor, Kecamatan Arjasa merupakan Desa binaan Politeknik Negeri Jember, arah pengembangan dari berbagai aspek diharapkan mampu menyelesaikan permasalahan yang ada. Melalui Kelompok Bina Warga (KBW) kegiatan pengabdian ini menitik beratkan pada teknologi Mesin Kritalisator yang digunakan sebagai alat untuk membuat suplemen herbal yang dapat digunakan untuk meningkatkan imun sehingga dapat mencegah penularan COVID 19. Sistem teknologi tersebut menggunakan metode pengaduk dengan motor penggerak, sumber pemanas berasal dari LPG. Saat ini dengan teknologi ini UKM KBW RT 5 sudah mengimplementasikan teknologi mesin kristalisator untuk membuat produk serbuk herbal berbahan jahe, kunyit merah dan berbagai bahan lain. Capaian target luaran berupa penerapan teknologi, aplikasi invensi, pemberdayaan wilayah tingkat KBW RT 5, dengan teknologi tersebut mampu memproduksi serbuk herbal mencapai 5-6kg perhari yang sebelumnya masih menggunakan cara konvensional dengan capaian kapasitas 2-3kg perhari. Dengan teknologi ini UKM tersebut mampu menghasilkan bubuk herbal dengan bahan baku rempah - rempah dengan hasil yang baik, kapasitas produksi meningkat dan keterampilan SDM meningkat.
\end{abstract}

Kata kunci — herbal, kristalisasi, covid 19

\begin{abstract}
Jember is one of the cities with the level of positive COVID 19 patients that have not experienced a significant decline with various invisible transmission media, various methods are used to prevent COVID 19 from spreading quickly. Several methods of prevention are spraying disinfectants, using proper sanitary ware, using herbal supplements for prevention in order to increase immunity and routine monitoring in each area. RT 5 Kopang Krajan Hamlet, Kemuning Lor Village, Arjasa District is a Jember State Polytechnic fostered village, the direction of development from various aspects is expected to be able to solve existing problems. Through the Community Development Group (KBW) this service activity focuses on the Crystallizer Machine technology which is used as a tool to make herbal supplements that can be used to increase immunity so as to prevent the transmission of COVID 19. The technology system uses a stirrer method with a motor driven, the heating source comes from. from $L P G$. Currently, with this technology, UKM KBW RT 5 has implemented crystallizer machine technology to make herbal powder products made from ginger, red turmeric, and various other ingredients. The output targets are the application of technology, application of inventions, empowerment of the KBWRT 5 level area, with this technology capable of producing herbal powders up to 5-6 $\mathrm{kg}$ per day which previously still used conventional methods with a capacity of 2-3 kg per day. With this technology, these SMEs are able to produce herbal powders with raw spices with good results, increase production capacity, and improve human resource skills.
\end{abstract}

Keywords - herbs, crystallization, covid 19 


\section{Pendahuluan}

Desa Kemuning Lor merupakan desa binaan Politeknik Negeri Jember yang menjadi prioritas sebagai fokus pengembangan Desa Mitra. Secara geografis Desa Kemuning Lor terletak pada wilayah daratan lebih kurang 100 900 MDPL dengan terdiri dari tanah kebun dan persawahan. Kondisi ketinggian yang cukup baik untuk berbagai tanaman karena persediaan air melimpah. Batas wilayah Desa Kemuning pada bagian utara adalah Hutan Negara, Timur Desa Darsono, Selatan Desa Baratan dan Barat Desa Bintoro. Desa yang memiliki luas $0.3 \%$ dari luas wilayah Kabupaten Jember membutuhkan peningkatan dari berbagai aspek, diharapkan dengan kegiatan binaan dari Politeknik Negeri Jember mampu meningkatkan menjadi desa mandiri dari berbagai aspek. Hal ini menjadi penting secara khusus dengan mengambil salah satu bagian dari daerah untuk diangkat menjadi kegiatan pengabdian masyarakat berbasis mitra binaan melalui kegiatan tersebut.

Pengusul menitik beratkan pada RT 5 Dusun Kopang Krajan yang menjadi wilayah pengabdian masyarakat. Pada RT tersebut terdapat ketua Kelompok Bina Warga (KBW) yang diketua Siti dengan anggota kelompok 28 orang darma wanita. Pada kegiatan tersebut sebelum adanya COVID 19 sering melakukan aktivitas rutin untuk menyelesaikan permasalahan warga, khususnya melalui ibu ibu darma wanita. Setiap 2 minggu sekali kegiatan dilakukan untuk menyelesaikan permasalahan yang ada dengan cara penyuluhan tentang PHB (Pola Hidup Bersih), konsumsi makanan sehat, sosialisasi dan pelatihan kegiatan peningkatan keterampilan melalui kewirausahaan, kegiatan darma lain yang memberikan profit pada KBW maupun non profit. Kondisi sekarang dengan adanya COVID 19 kegiatan tersebut mulai dikurangi, kegiatan mengarah konsentrasi kepada pencegahan COVID 19, antisipasi COVID 19 dengan berjemur, minum vitamin, olahraga rutin, penyemprotan area RT, pembuatan minuman herbal oleh KBW dengan cara manual, sehingga konsistensi hasil herbal belum optimal. Pengusul mengarah pada solusi permasalahan berupa pembuatan suplemen herbal dengan bahan rempah alam menggunakan Mesin Kristalisator untuk pembuatan suplemen berbentuk bubuk instan yang dapat dijadikan minuman agar mampu meningkatkan imun warga dalam antisipasi pencegahan COVID 19 dan diharapkan menjadi kegiatan unit usaha untuk KBW yang lebih produktif dan mendapatkan profit dari unit usaha tersebut.

Pada KBW tersebut diketuai oleh Siti untuk mengkoordinir warga RT 5 dengan anggota 28 orang wanita dalam kegiatan Penyuluhan, Pelatihan, dan Peningkatan SDM dalam kegiatan usaha melalui kegiatan pengabdian ini sangat dibutuhkan pengetahuan tentang teknologi pengolahan agar suplemen menghasilkan produk dengan ekstrak tetap terjaga. Saat ini dengan adanya Mesin Kristalisator dapat digunakan untuk memproduksi suplemen berbentuk bubuk dengan bahan baku herbal yang diolah, pada mesin ini disediakan katup kontrol pemanas dan sistem pengaduk continue untuk menjaga komposisi bahan yang diolah tetap konstan terjaga. Dengan situasi kondisi COVID 19, mesin ini dibutuhkan untuk mengolah suplemen herbal sebagai minuman instan untuk meningkatkan imun warga agar dapat mencegah COVID 19. Saat ini dengan menggunakan mesin kristalisator UKM dapat memproduksi 4-6 $\mathrm{kg}$ per hari dengan berbagai macam varian bahan baku Gambar 1 . Kemasan per produk $200 \mathrm{~g}$ ekstrak jahe dijual dengan harga Rp. 35.000,-. Jika rata - rata per hari $4 \mathrm{~kg}$ makan omset harian lebih kurang $\mathrm{Rp}$. $700.000,-$.

\section{Target dan Luaran}

Sasaran kegiatan Pengabdian Kepada Masyarakat adalah Kelompok Bina Warga (KBW) pada RT 5 Dusun Kopang Krajan, Desa Kemuning Lor, Arjasa, Jember yang diketuai Siti dengan anggota kelompok 28 orang darma wanita

\subsection{Target}

Target kegiatan pengabdian kepada masyarakat adalah fokus pada pencegahan COVID 19 yang meliputi :

a. Mampu menerapkan PHB (Pola Hidup Bersih) serta mengkonsumsi makanan sehat sehingga imun meningkat; 
b. Peningkatan sinergi kelembagaan IPTEK perguruan tinggi kepada masyarakat;

c. Peningkatan produktivitas, nilai tambah, kualitas dan daya saing mitra dalam olahan produk minuman herbal instan;

d. Peningkatan kesejahteraan masyarakat melalui peningkatan kapasitas dan kualitas produksi minuman herbal instan;

e. Secara khusus mampu memanfaatkan produk teknologi kristalisasi minuman herbal dengan kapasitas mesin kristalisator $3 \mathrm{~kg}$ per jam .

\subsection{Luaran}

Table 1. Jenis Luaran dan Indikator Capaian

\begin{tabular}{|c|c|c|}
\hline No. & Luaran & $\begin{array}{l}\text { Indikator } \\
\text { Capaian }\end{array}$ \\
\hline \multirow[t]{11}{*}{1} & $\begin{array}{l}\text { Semua aspek pada pencegahan } \\
\text { COVID 19: }\end{array}$ & \\
\hline & $\begin{array}{l}\text { Pelatihan pengolahan dan } \\
\text { penentuan komposisi campuran } \\
\text { suplemen dari ekstrak bahan herbal }\end{array}$ & Tercapai \\
\hline & Peningkatan Kapasitas & Tercapai \\
\hline & $\begin{array}{l}\text { Pemahaman dan implementasi } \\
\text { penggunaan teknologi kristalisasi } \\
\text { minuman herbal bubuk }\end{array}$ & Tercapai \\
\hline & $\begin{array}{l}\text { Implementasi produksi dan } \\
\text { pengemasan minuman herbal } \\
\text { instan }\end{array}$ & Tercapai \\
\hline & Peningkatan kapasitas produksi & Tercapai \\
\hline & $\begin{array}{l}\text { Pengelolaan kapasitas produksi dan } \\
\text { permintaan pasar }\end{array}$ & Tercapai \\
\hline & $\begin{array}{l}\text { Menentukan harga jual dan biaya } \\
\text { produksi }\end{array}$ & Tercapai \\
\hline & $\begin{array}{l}\text { Manajemen keuangan dan } \\
\text { operasional }\end{array}$ & Tercapai \\
\hline & SDM unggul dan terampil & Tercapai \\
\hline & $\begin{array}{l}\text { Memberdayakan ibu-ibu darma } \\
\text { wanita }\end{array}$ & Tercapai \\
\hline 2 & Publikasi Media Massa & Published \\
\hline 3 & $\begin{array}{l}\text { Publikasi artikel pada Jurnal J- } \\
\text { DINAMIKA }\end{array}$ & Published \\
\hline
\end{tabular}

\section{Metodologi}

Adapun metode pelaksanaan yang dilakukan adalah sebagai berikut :

Studi pustaka dan observasi lapang a. Studi pustaka yang dibutuhkan untuk mendesain mesin katalisator dengan kapasitas $3 \mathrm{~kg}$ per jam yang mudah digunakan dan minimum perawatan.

b. Observasi lapang yang dilakukan adalah:

- Identifikasi bahan baku yang ada di mitra;

- Mengamati peralatan produksi (pengolahan) minuman herbal menjadi bubuk instan yang digunakan mitra;

- Mengamati pengelolaan usaha minuman herbal yang dijalankan mitra;

- Mengamati model pengolahan yang dilakukan mitra

Prosedur kerja yang diterapkan pada kegiatan ini adalah sebagai berikut:

a. Persiapan;

b. Studi pustaka

Studi pustaka merupakan tahap paling awal. Pencarian literatur karya ilmiah, jurnal, dan data-data pendukung terkait apa yang akan digunakan dalam kegiatan PKM ini.

c. Survei lapang

Tahapan ini meliputi pengumpulan data dan informasi di lapangan yang diperlukan untuk pengerjaan dari hasil tahap pertama. Tahap ini meliputi metode wawancara dan observasi.

d. Pengumpulan dan pengolahan data awal

e. Penyusunan kelengkapan teknologi yang memadai khususnya mesin kristalisasi. Mesin tersebut sangat dibutuhkan untuk meningkatkan kapasitas produksi;

f. Perancangan alat dan mesin bagi mitra untuk mengimplementasikan teknologi kristalisasi;

g. Pelatihan dan Pendampingan bagi mitra;

h. Monitoring dan evaluasi;

i. Pembuatan laporan.

Deskripsi mesin kristalisasi : Desain mesin kristalisator berkapasitas $3 \mathrm{~kg}$ per produksi, dibuat dengan rangka hollow dengan perhitungan desain konstruksi dari program gambar Solidworks untuk mengetahui kekuatan material logam terhadap beban yang akan diterima, beban berupa motor penggerak dan gear rasio putaran, serta bahan baku yang akan diaduk. Desain secara visual harus mampu lebih besar dari desain aktual. Sehingga desain menjadi bagian 
penting untuk menentukan pilihan dalam kapasitas mesin.

\section{Pembahasan}

Dalam membantu mitra untuk menyelesaikan permasalahan maka telah dilakukan tahapan konkret untuk menyelesaikan permasalahan yang ada yang meliputi :

\subsection{Peningkatan Kapasitas Produksi}

Solusi yang akan diberikan untuk menyelesaikan permasalahan ini diselesaikan melalui pendampingan pada aspek SDM dan Teknik.

Pendampingan pada aspek SDM meliputi : 1) Pelatihan penggunaan mesin yang akan diberikan, dengan memberikan informasi SOP setiap mesin yang akan digunakan sebagai penerapan teknologi kristalisator; 2) Pelatihan perawatan penggunaan mesin agar sesuai dengan SOP; 3) Manajemen inovasi dan kebaruan produk sebagai salah satu langkah pengelolaan pasar.

Pendampingan pada aspek teknik yaitu penentuan komposisi campuran minuman herbal sesuai dengan permintaan pasar

\subsection{Manajemen Keuangan}

Solusi yang akan diberikan untuk menyelesaikan permasalahan ini diselesaikan melalui pendampingan pada aspek SDM. Pendampingan pada aspek SDM yaitu memberikan Pelatihan ekonomi Teknik sebagai evaluasi neraca keuangan di KBW.

\subsection{Manajemen Produksi}

Solusi yang akan diberikan untuk menyelesaikan permasalahan ini adalah memberikan uraian manajemen produksi dari yang sebelumnya konvensional menggunakan teknologi terkini.

Setelah kegiatan penyelesaian masalah mitra didapatkan hasil seperti pada tabel 2 berikut ini.
Table 2. Hasil Kegiatan PKM

\begin{tabular}{lll}
\hline No. & Kegiatan & Hasil Kegiatan \\
\hline 1 & Pelatihan & - Mesin Kristalisator bekerja \\
& Penggunaan & sesuai dengan \\
& Mesin & kapasitasnya \\
& Katalisator & - Kinerja Mesin Kristalisator \\
& & Bekerja dengan baik \\
& & - Mesin Kristalisator mudah \\
& & digunakan dan perawatan \\
& & mudah \\
2 & Pembekalan & Mitra mampu menganalisis \\
& Manajemen & keuangan biaya bahan baku, \\
& Keuangan & operasional dan harga jual \\
& & produk \\
3 & Pembekalan & Kapasitas produksi dari \\
& Manajemen & sebelumnya 2-3 kg menjadi \\
& Produksi & 5-6 kg \\
\hline
\end{tabular}

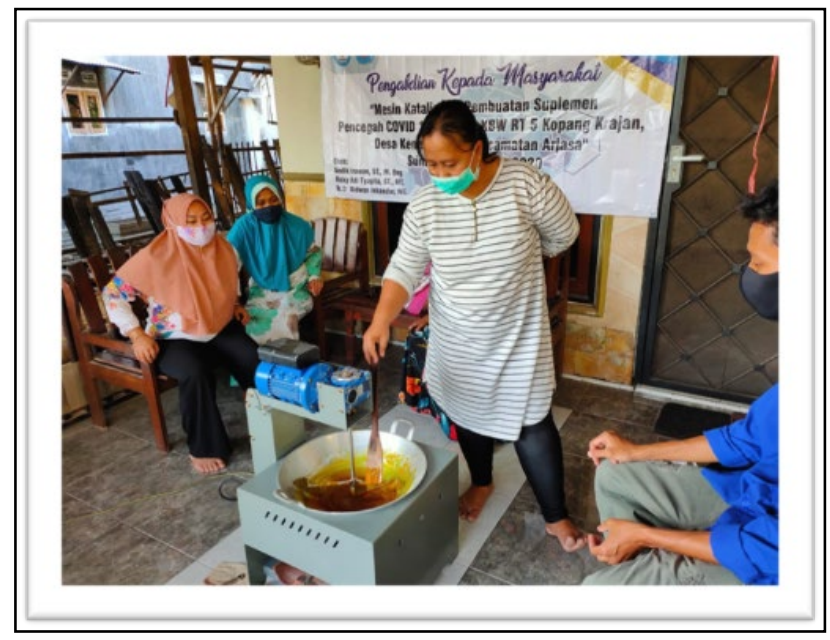

Figure 1. Pelatihan Penggunaan Mesin Katalisator

\section{Kesimpulan}

\subsection{Kesimpulan}

Kesimpulan kegiatan Pengabdian meliputi :

a. Kegiatan telah dilaksanakan $100 \%$

b. Mesin Kristalisator telah diterima dan digunakan secara baik

c. Pengoperasian mesin dapat digunakan mudah dan aman

d. Peningkatan kapasitas produksi dari $2-3 \mathrm{~kg}$ per hari menjadi $5 \mathrm{~kg}$ per hari 


\subsection{Saran}

Semoga program Pengabdian Kepada Masyarakat sumber dana PNBP senantiasa berkelanjutan sehingga dapat mengakselerasi proses hilirisasi produk teknologi hasil penelitian para tenaga pendidik agar dapat dimanfaatkan oleh masyarakat.

\section{Ucapan Terima Kasih}

Ucapan terima kasih yang sebesarbesarnya ditujukan atas bantuan, dukungan, dan kerja sama dari berbagai pihak yakni : 1) Politeknik Negeri Jember melalui pendanaan PNBP, 2) Kelompok Bina Warga RT 5 Dusun Kopang Krajan, Desa Kemuning Lor, Kecamatan Arjasa, yang diketuai oleh Ibu Siti yang berkenan menjadi mitra pada kegiatan pengabdian ini.

\section{Daftar Pustaka}

[1] Fatma, Z. 2011. Analisis Fungsi Produksi dan Efisiensi Usahatani Kopi Rakyat di Aceh Tengah. Tesis. Program Pascasarjana. Institut Pertanian Bogor. Bogor.

[2] Thamrin, S. 2014. Faktor-faktor yang Mempengaruhi Produksi Usahatani Kopi Arabika di Kabupaten Enrekang Sulawesi Selatan. Agric, 26(1), 1-6. https://doi.org/10.24246/agric.2014. v26.i1.p1-6 